\title{
Laparoscopic surgery management of Hydronephrosis secondary to Left Paraduodenal Hernia in cryptorchid: Case report and a literature review
}

xin Wang ( $\square$ vivianwang1983@163.com )

Tianjin children's hospital

\section{Yong Guan}

tianjin chidren's hospital

Yong Wu

tianjin chialdren's hospital

QingYa Meng

Tianjin Children's Hospital

\section{Case report}

Keywords: paraduodenal hernia, hydronephrosis, cryptorchidism, laparoscopic surgery

Posted Date: February 26th, 2020

DOl: https://doi.org/10.21203/rs.2.24657/v1

License: (c) (1) This work is licensed under a Creative Commons Attribution 4.0 International License.

Read Full License 


\section{Abstract}

Rationale Left paraduodenal hernia (PDH) is a mesenterico-parietal hernia with retroperitoneal retrocolic herniation of the small bowel into a sac formed by a peritoneal fold located near the fourth portion of the duodenum. It's a rare cause of hydronephrosis by compressed the upper left ureter. Traditionally, PDH are treated by laparotomy. Patient concerns An 8-year-old boy's primary purpose was the treatment of cryptorchidism. But hydronephrosis was detected and it was induced by left paraduodenal hernia. Diagnosis Diagnostic laparoscopic exploration confirmed the diagnosis left paraduodenal hernia secondary hydronephrosis. Cryptorchidism was the primary purpose of treatment. Interventions The patient was treated with laparoscopic surgery, fixed left paraduodenal hernia, released the ureteropelvic junction obstruction (UPJO) and treated hydronephrosis. Out comes Secondary surgery for treating cryptorchidism would be performed and the long-term follow up was necessary. Lessons This case suggests us a rare cause of hydronephrosis in children. Every why has a wherefore. We must pay much attention to any unusual details in our medical work even though these details aren't related to our primary objects.

\section{Background:}

Internal hernia results from protrusion of one or more abdominal viscera through an intraparietal opening with the herniated viscera remaining inside the peritoneal cavity. And it account for less than $1 \%$ of all abdominal hernias ${ }^{(1)}$.Paraduodenal hernia (PDH) is the most common rare internal hernia, accounting for about $50 \%$ of all internal hernias. About 3 quarters of PDH are left, and the male-to-female ration is 3:1. Some cases $(<1 \%)$ caused small bowel obstruction ${ }^{(2)}$ and more rare cases caused hydronephrosis. It's difficult to make a correct diagnosis of internal hernia and the misdiagnosis may lead to serious outcomes. One of the internal hernia feature is that the patients suffered persistent intestinal obstruction without an alternative cause ${ }^{(3)}$. But in rare cases, consideration for internal hernia should be maintained for patients with features of hydronephrosis. Most of hernia causing hydronephosis is sliding inguinal hernia. Significant herniation may cause ureteral obstruction leading to hydronephrosis ${ }^{(4)}$.

Cryptorchidism is one of the most frequent congenital pathologies, affecting from 2 to $5 \%$ of boys. Approximately $7 \%$ of child patients with inguinal hernias also present with cryptorchidism but PDH is rare. At present, there is no evidence to prove the connection between cryptorchidism and hernia. This case described the details of a patient with a left-sided PDH induced hydronephrosis with cryptorchidism. The patient agreed the publication of this case report and accompanying images and signed the informed consent. Tianjin Children's Hospital ethics committee has approved this case.

\section{Case Presentation:}

This patient first presented at 8 years of age with enuresis symptoms. The chief complaint was that the parents found the absence of left testes. And other hospital's diagnosis was Cryptorchidism. His bodymass index is 14.2. The Physical examination is normal. Rectal examination was normal, left testis was 
topic, without alterations, and right testis was not found at scrotum. But the urinary B-ultrasound showed left hydronephrosis. It was unusual in cryptorchid. The renal function including serum creatinine $(\mathrm{Cr})$ and blood urea nitrogen (BUN) was normal. To investigate the cause of hydronephrosis, the enhancedscanning computed tomography (CT) was performed revealing findings consistent with left UPJO (Fig. 1). With this information we planned on performing a laparoscopic exploration and Anderson-Hynes pyeloplasty to relieve the hydronephrosis. A 10-mm port was inserted infraumbilically using Hasson technique, and the others located in below the umbilicus and epigastric region. After checking the abdomen cavity completely, we found that the hyperexpansion of renal pelvis and left paraduodenal hernia. The collapsed small bowel loops were traced upward through a defect in the left paraduodenal and interior descending colon. The hernial sac compressed the upper ureter of the left ureter and induced the hydronephrosis (Fig. 2). It appeared small bowel dysplasia, the diameter of bowel was smaller than the normal, but without ischemic signs. The hernia was reduced by traction and division of the sac. An incision was made in the hernia sac wall and the entire sac was freed. The bowel was put in an anatomical position and the fossa defect was sutured with a continued silk suture. The inferior mesenteric vein (IMV) and the branch of left colonic artery formed anterior wall of the neck of the hernia sac and compressed the intestinal canal. After 20 minutes of blocking blood flow, we confirmed that the intestinal peristalsis, color and blood supply were normal. The UPJ "obstruction" was determined to be consistent with a partial obstruction from external compression and the planned pyeloplasty was not performed. The postoperative period was uneventful without local and general complication. And we retrospectively reviewed CT showed that, at the level of the renal vessels shows a horseshoe appearance of the bowel loops that contain the jejunal vessels radiating inside the hernial sac (Fig. 1). It was a nonspecific presentation of PDH without obstruction. And we didn't discover the PDH preoperatively. The ultrasound showed that hydronephrosis was remitting during the follow up for 12 weeks and caliectasis was disappeared. Three months later, a second procedure would be performed to fix the cryptorchidism. Recently, the CT 2 years after laparoscopic PHD repair showed that the hydronephrosis was remitted (Fig. 3). And the BUN and $\mathrm{Cr}$ is still normal.

\section{Discussion}

Dr. Treitz described the PDH first in 1857 and Dr. Jonnesco classified it in right and left in 1889. A type of malrotation is the currently accepted mechanism of PDH, which is described by Andrews first. The midgut rotation occurs the 5 th to 11 th weeks of gestation and the mesentery fused the posterior abdominal structures from the right iliac fossa to the ligament of Treitz. There are various clinical manifestations: recurring abdominal pain, acute obstruction and asymptomatic. Left PDH is the most common internal herniation, but it tends to present too many clinical features to early diagnosis ${ }^{(5)}$. Laboratory tests are often of little significance. The physical examination is frequently inconclusive only when the hernia is big enough to make an abdominal mass and the eccentric abdominal distention situated on the corresponding side of the hernia. Up to $50 \%$ of internal hernia was diagnosed by autopsy, imaging exams and unrelated abdominal surgeries ${ }^{(6)}$. Computerized tomography (CT) has improved the diagnostic ability of PDH, especially for the PDH without specific presention ${ }^{(7)}$. But there are only about $10-15 \%$ of cases 
discovered preoperatively ${ }^{(6)}$. However, there are only a few reports of the CT features of PDH. The common radiography can give information regarding the intestinal segment involved and the extension of the intestinal obstruction. Without a specific radiographic diagnosis such as obstruction, this rare condition may be missed ${ }^{(8)}$. As our case, there is no intestinal obstruction and the PDH was missed preoperatively. Therefore, we hope to show the case to get other pediatricians and urological surgeons talking about it. It was a non-specific presentation PDH without obstruction. Even if there is no intestinal obstruction, we should not ignore PDH. The treatment of left PDH is surgical repair because of its about $50 \%$ life-threatening complication. The aims of surgery are resection of ischemic intestinal segment, repair of herniated structures and closure of hernia orifice. Prevention of recurrence of hernia through abnormal orifice is very important. It is unusual to use prosthesis placement to repair the defect, and the mesh implants are used to repair recurrent hernia and large defect ${ }^{(9)}$. Open surgery is the conventional repair method for the left PDH. In 1998, Dr. Uematsu reported the first laparoscopic repair ${ }^{(10)}$. Laparoscopic diagnosis and repair surgery is a good method to treat the left PDH. Reviewed 23 previously reported cases (Table 1), we found that there were just two of these cases required conversion to laparotomy because of a gangrenous bowel in one and tight adhesions around the inferior mesenteric vein region in the other. 4 of 23 cases required excision of the sac to reduce the bowel loops. 3 cases' defects were closed and other's defects varied between $2 \mathrm{~cm}$ and $8 \mathrm{~cm}$ (Table 1). 
Table 1

Cases of left PDH reported in the literature

\begin{tabular}{|c|c|c|c|c|c|c|c|}
\hline Authors & Sex & Age & $\begin{array}{l}\text { Size of } \\
\text { defect }(\mathrm{cm})\end{array}$ & $\begin{array}{l}\text { Sac } \\
\text { excised }\end{array}$ & $\begin{array}{l}\text { Defect } \\
\text { closed }\end{array}$ & $\begin{array}{l}\text { Postoperative } \\
\text { LOS (days) }\end{array}$ & $\begin{array}{l}\text { Laparoscopy } \\
\text { completed }\end{array}$ \\
\hline Lee et al. & $\mathrm{F}$ & 74 & 3 & $N$ & $Y$ & 4 & $Y$ \\
\hline $\begin{array}{l}\text { Jeong et } \\
\text { al. }\end{array}$ & $M$ & 52 & 5 & $N$ & $Y$ & 5 & $Y$ \\
\hline $\begin{array}{l}\text { Cundy et } \\
\text { al. }\end{array}$ & $M$ & 55 & 6 & $\mathrm{~N}$ & $Y$ & 6 & $\mathrm{~N}$ \\
\hline $\begin{array}{l}\text { Jeong et } \\
\text { al. }\end{array}$ & $\mathrm{F}$ & 58 & 6 & $N$ & $Y$ & 5 & $Y$ \\
\hline $\begin{array}{l}\text { Palanivelu } \\
\text { et al. }\end{array}$ & $M$ & 44 & 7 & $\mathrm{~N}$ & $Y$ & 5 & $Y$ \\
\hline $\begin{array}{l}\text { Palanivelu } \\
\text { et al. }\end{array}$ & $M$ & 49 & 8 & $\mathrm{~N}$ & $Y$ & 2 & $Y$ \\
\hline $\begin{array}{l}\text { Palanivelu } \\
\text { et al. }\end{array}$ & $\mathrm{F}$ & 54 & 9 & $\mathrm{~N}$ & $Y$ & 2 & $Y$ \\
\hline Nam et al. & $M$ & 1 & 3 & $\mathrm{~N}$ & $Y$ & 5 & $Y$ \\
\hline Nam et al. & $\mathrm{F}$ & 12 & 5 & $N$ & $Y$ & 5 & $Y$ \\
\hline $\begin{array}{l}\text { Fukanage } \\
\text { et al. }\end{array}$ & $M$ & 51 & 5 & $\mathrm{~N}$ & $Y$ & 9 & Y \\
\hline $\begin{array}{l}\text { Coakley et } \\
\text { al. }\end{array}$ & $M$ & 25 & 6 & $Y$ & $\mathrm{~N}$ & 3 & $\mathrm{~N}$ \\
\hline $\begin{array}{l}\text { Parmar et } \\
\text { al. }\end{array}$ & $M$ & 38 & 8 & Y & NM & 3 & $\mathrm{Y}$ \\
\hline $\begin{array}{l}\text { Azuma et } \\
\text { al. }\end{array}$ & $M$ & 60 & 3 & $\mathrm{~N}$ & Y & 6 & $Y$ \\
\hline $\begin{array}{l}\text { Siddika et } \\
\text { al. }\end{array}$ & $M$ & 35 & 3 & $\mathrm{~N}$ & $Y$ & 6 & $Y$ \\
\hline $\begin{array}{l}\text { Khalaileh } \\
\text { et al. }\end{array}$ & $\mathrm{F}$ & 53 & 4 & $\mathrm{~N}$ & $Y$ & 3 & $Y$ \\
\hline $\begin{array}{l}\text { Rollins et } \\
\text { al. }\end{array}$ & $M$ & 21 & 4 & $\mathrm{~N}$ & Y & 2 & $Y$ \\
\hline $\begin{array}{l}\text { Uematsu } \\
\text { et al. }\end{array}$ & $M$ & 44 & 5 & $\mathrm{~N}$ & Y & 28 & $Y$ \\
\hline
\end{tabular}

PDH, paraduodenal hernia ; Y, yes; N, NO; F, female; M, male; LOS, length of stay; NM: not mentioned 


\begin{tabular}{|c|c|c|c|c|c|c|c|}
\hline Authors & Sex & Age & $\begin{array}{l}\text { Size of } \\
\text { defect }(\mathrm{cm})\end{array}$ & $\begin{array}{l}\text { Sac } \\
\text { excised }\end{array}$ & $\begin{array}{l}\text { Defect } \\
\text { closed }\end{array}$ & $\begin{array}{l}\text { Postoperative } \\
\text { LOS (days) }\end{array}$ & $\begin{array}{l}\text { Laparoscopy } \\
\text { completed }\end{array}$ \\
\hline $\begin{array}{l}\text { Hussein et } \\
\text { al. }\end{array}$ & $M$ & 59 & 5 & $\mathrm{~N}$ & $Y$ & 3 & $Y$ \\
\hline $\begin{array}{l}\text { Moon et } \\
\text { al. }\end{array}$ & $M$ & 18 & 2 & $Y$ & $Y$ & 2 & $Y$ \\
\hline $\begin{array}{l}\text { Assenza } \\
\text { et al. }\end{array}$ & $M$ & 67 & 3 & $\mathrm{~N}$ & $\mathrm{~N}$ & 4 & $Y$ \\
\hline $\begin{array}{l}\text { Uchiyama } \\
\text { et al. }\end{array}$ & $\mathrm{F}$ & 80 & 5 & $\mathrm{~N}$ & $\mathrm{~N}$ & 3 & $Y$ \\
\hline $\begin{array}{l}\text { Gaurav et } \\
\text { al. }\end{array}$ & M & 36 & 4 & $\mathrm{~N}$ & $Y$ & 3 & $Y$ \\
\hline $\begin{array}{l}\text { Gaurav et } \\
\text { al. }\end{array}$ & $M$ & 42 & 4 & $Y$ & $Y$ & 3 & $Y$ \\
\hline
\end{tabular}

In our cases, the follow-up CT 2 years after operation showed the hydronephrosis was remitted and the PDH had been recovered. It may also be interpreted as indirect proof of PDH caused hydroneprosis. But there was no similar case had been reported. PDH are the rare internal hernia common causing obstruction. It's a rare case in our knowledge that PDH induced hydronephrosis. Therefore, we'd like to present this case to avoid similar surgical risk and introduce a possible cause of hydroneprosis. And at last, we'll treat his cryptorchidism by a secondary operation. And the long-term follow up is necessary.

\section{Conclusion:}

This case suggests us a rare cause of hydronephrosis in children. However, there are only few cases of PDH discovered preoperatively. If necessary, laparoscopic exploration is a good method of diagnosis and a good treatment for choose. Every why has a wherefore. We must pay much attention to any unusual details in our medical work even though these details are not our primary objects.

\section{Abbreviations}

$\mathrm{PDH}=$ paraduodenal hernia, $\mathrm{CT}$ = computed tomography, UPJO = ureteropelvic junction obstruction, IMV = inferior mesenteric vein

\section{Declarations}

Ethics approval and consent to participate: Tianjin Children's Hospital ethics committee has approved this case. The informed consent was obtained for diagnostic laparoscopy. The parents and legal guardian of the patient agreed the method, surgery protocol, publication of this article and accompanying 
images and signed the informed consent. We confirm that all methods were carried out in accordance with guideline.

Consent for publication: The patient agreed the publication of this case report and accompanying images and signed the informed consent.

Availability of data and materials: Not applicable

Competing interests: The authors declare that they have no competing interests.

Funding: National Natural Science Foundation of China (to Xin Wang, No.81600073). The funders had no rolein study design, data collection and analysis, decision to publish, or in the preparation of the manuscript.

\section{Author information:}

\section{Affiliations:}

Department of Pediatric Surgery, Tianjin Children's Hospital, No.238 LongYan Road, Tianjin 300134, PR China.

Xin Wang, Yong Guan, Yong Wu, QingYa Meng

Contributions: All authors participated in the patient's care. Yong Guan and Xin Wang performed the surgeries described in this report. Xin Wang and Yong Wu constructed the conception and design of this report. QingYa Meng prepared the draft of the manuscript. All authors read and approved the final manuscript.

Acknowledgements: We thank all patients treated in our department, and all the rest of doctors and nurses in the department for wonderful clinical care.

\section{References}

1. Husain A, Bhat S, Roy AK, Sharma V, Dubey SA, Faridi MS. Internal Hernia through Paraduodenal Recess with Acute Intestinal Obstruction: A Case Report. Indian J surg. 2012;74:354-5.

2. Kulendran K, Keogh C, Chiam HC. Laparoscopic repair of a left paraduodenal hernia. ANZ J Surg. 2019;89: E172-E173.

3. Ginsberg DL, Sussman N. Gabapentin as prophylaxis against steroid-induced mania. Can J Psychiatry. 2001;46:455-6.

4. Massoud W, Eschwege P, Hajj P, et al. Hydronephrosis secondary to sliding inguinal hernia containing the ureter. Urol J. 2011;8:333-4.

5. Kabbani D, Salem A, Holloway DK. Paraduodenal herniation: An internal herniation in a virgin abdomen. Int J Surg Case Rep. 2014;5:1148-50. 
6. Assenza M, Rossi D, Rossi G, et al. Laparoscopic management of left paraduodenal hernia. Case report and review of literature. G Chir. 2014;35:185-9.

7. Parmar BP, Parmar RS. Laparoscopic management of left paraduodenal hernia. J Minim Access Surg. 2010;6:122-4.

8. Olazabal A, Guasch I, Casas D. Case report: CT diagnosis of nonobstructive left paraduodenal hernia. Clin Radiol. 1992;46:288-9.

9. Fukada T, Mukai H, Shimamura F, Furukawa T, Miyazaki M. A causal relationship between right paraduodenal hernia and superior mesenteric artery syndrome: a case report. J Med Case Rep. 2010;4:159.

10. Uematsu T, Kitamura H, Iwase M, Yamashita K, Ogura H, Nakamuka T, et al. Laparoscopic repair of a paraduodenal hernia. Surg Endosc. 1998;12:50-2.

\section{Figures}




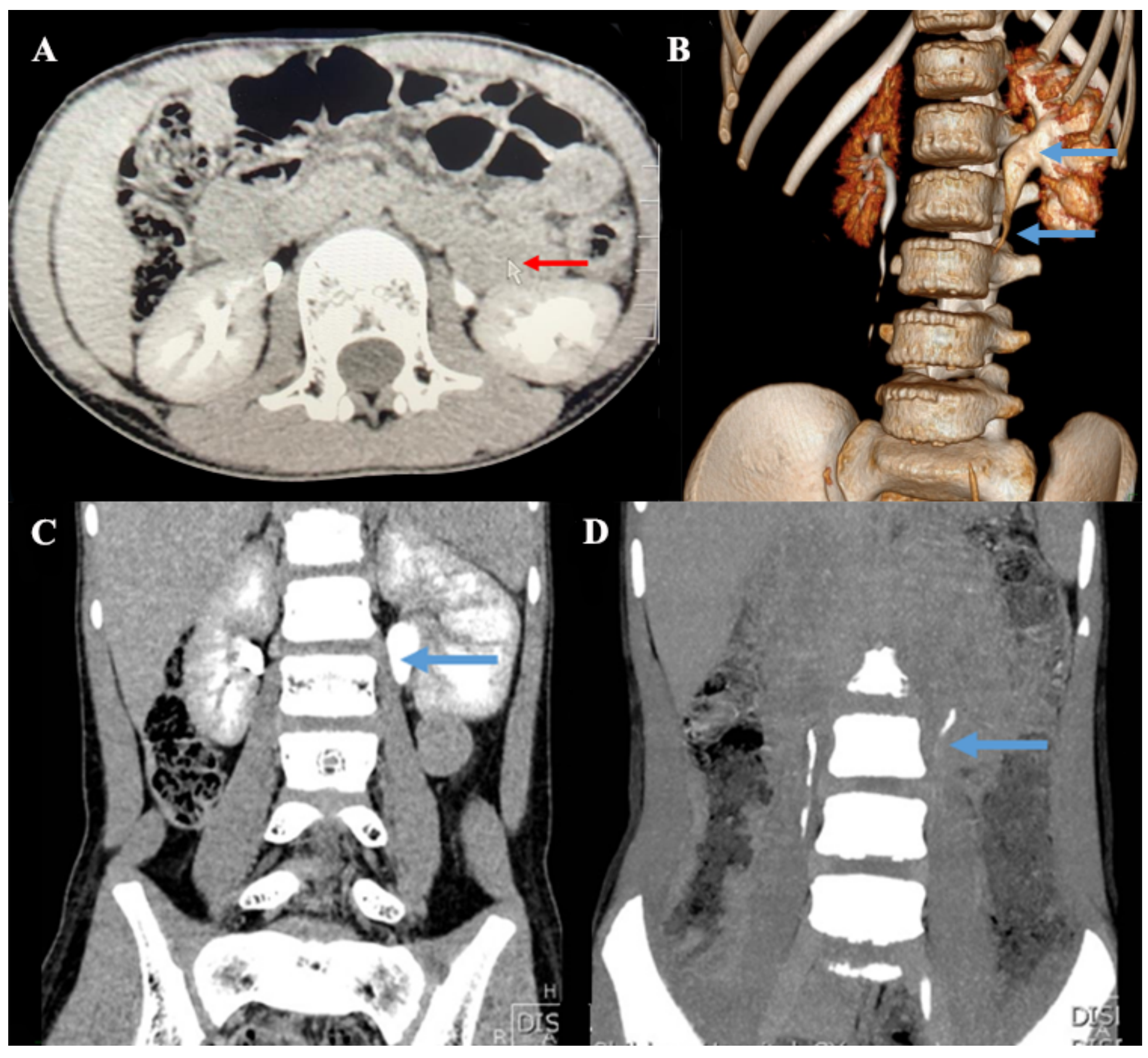

\section{Figure 1}

The enhanced-scanning CT show A: CT section at the level of the renal vessels shows a horseshoe appearance of the bowel loops that contain the jejunal vessels radiating inside the hernial sac. B: Left hydronephrosis (upper arrow) and ureter pelvic junction obstruction (lower arrow), C: Left hydronephrosis, D: ureter pelvic junction obstruction. 


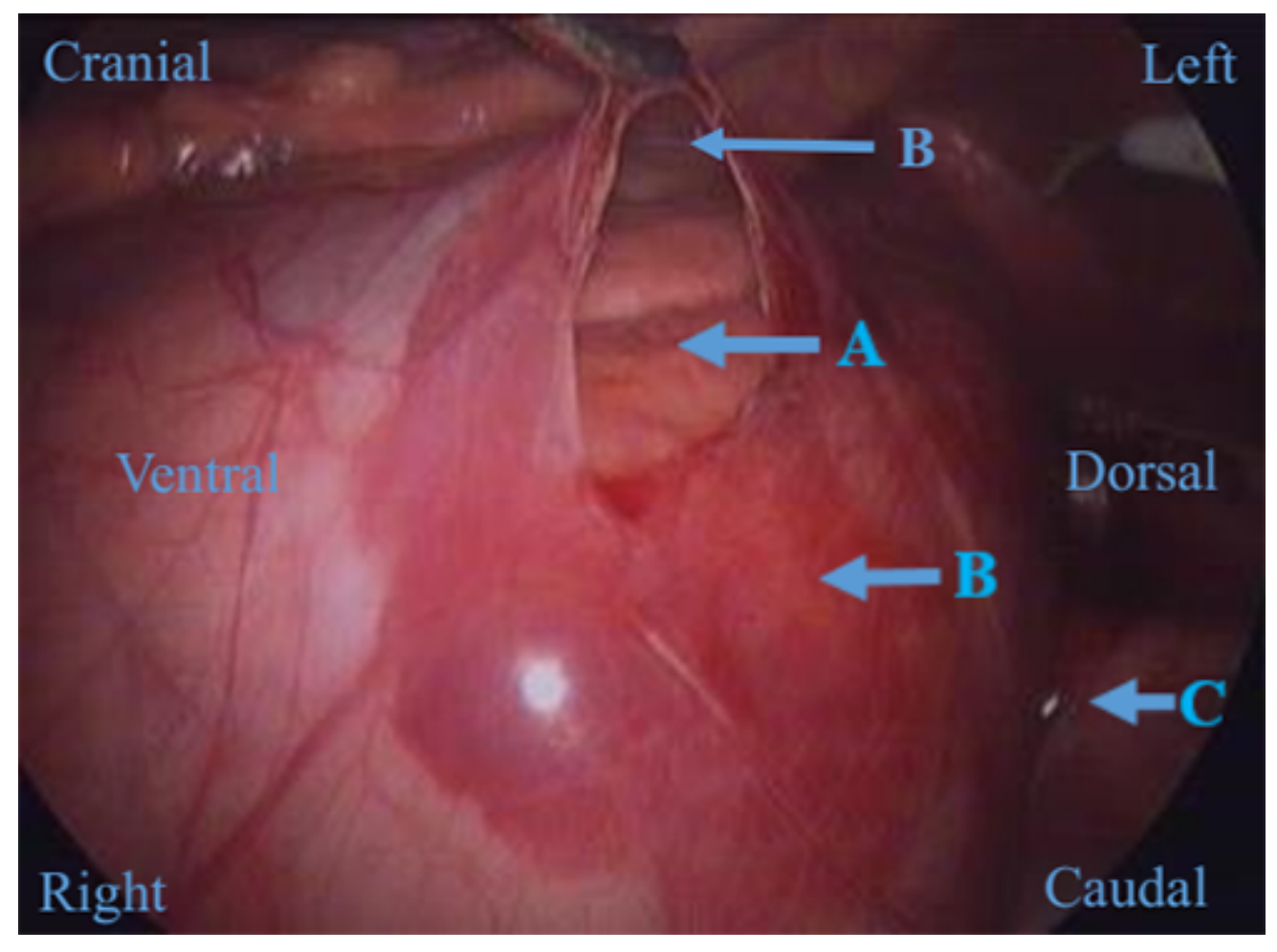

Figure 2

The patient was lying on the right side while we performed the surgery. The observation hole was near the umbilicus. Intra-operatively it was observed that small-bowel loops were lying within a hernial sac. Upper end of ureter was located in retroperitoneum, behind the hernia sac. The sac was opened with an ultrasonic shears and the bowel was freed up. The hernia sac compressed the upper ureter of the left ureter and induced the hydronephrosis. A: small intestine, B: hernia sac, C: lateral peritoneum

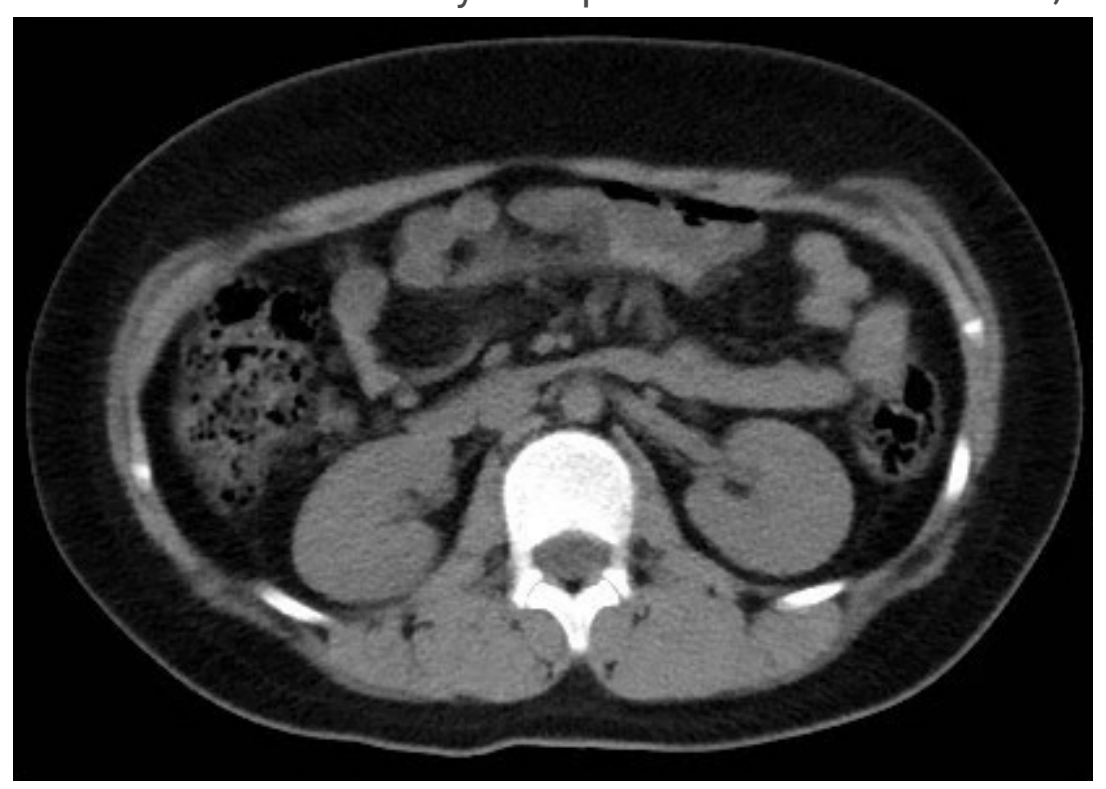

\section{Figure 3}

The CT 2 years after laparoscopic PDH repair showed that the hydronephrosis was remitted 